\title{
第三次全国国土调查项目成果质量控制方法 \\ Quality Control Method for Results of the Third National Land Survey Project \\ 李倩 杨孝伟
}

Qian Li Xiaowei Yang

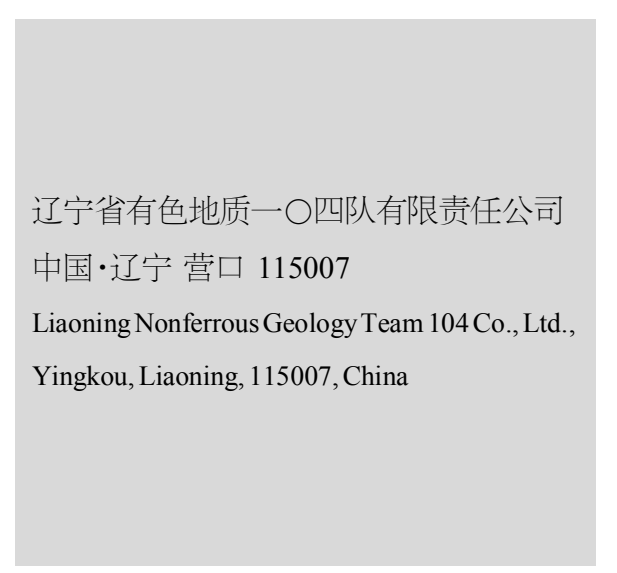

\section{1 引言}

在开展三调工作时, 具有更为先进的调查手段, 更高的 调查精度, 同时其调查内容也具有更高的全面性。在进行具 体工作过程中, 科学控制项目成果质量具有极其重要的价 值, 能够实现调查精度的有效提升, 为了对其具有更为明确 的认知, 特此展开本次研究。

\section{2 三调技术特点}

首先具有更为先进的调查手段, 在具体进行三调工作 时,高度集成大数据分析,通信技术, $3 \mathrm{~S}$ 技术和互联网+实现 的现代科技是其工作人员采用的最新技术, 科学应用带有方 向传感器和卫星定位功能的平板电脑或手机, 基于国家相关 部门提供的互联网加举证软件对举例说明, 实地照片拍摄时 间，拍摄方位角以及实地 GNSS 坐标等综合信息进行加密打 包, 同时向国家举证平台报送, 国家相关部门能够对其进行 更为有效的控制。与此同时, 具有更高的调查精度, 有效落实 城乡一体化。在农村进行调查过程中,需要控制其比例尺, 不 能低于 $1: 5000$, 而在城镇村内部进行调查过程中, 需要将其 比例尺控制在 1:2000, 如果建设地区具有更高管理需求,相 关部门可以将群精度要求适当提升[1]。进行三调工作的主要 目的对于土地利用相关数据进行全面细化与科学完善, 确保 各级工作人员能够全面掌握土地资源变化和土地利用现状。 因此,基于细化规则和统一标准对其数据成果质量提出了更 高的要求, 确保全过程控制的有效落实科学引进监理制度, 严格基于相关规定对这期各个施工环节进行自查和互查, 作
业单位还需要确保 AI 及检查制度的有效落实, 确保能够对 其相关问题进行及时检查和有效处理。

\section{3 项目成果质量控制策略}

\section{1 科学改进组织管理}

在进行测绘工作时, 科学构建质量管理体系是其各项工 作有序开展的重要条件, 测绘作业单位必须对其相关组织进 行科学有效的管理,合理构建质量管理制度,对其各级工作 人员进行教育培训, 实现相关人员职业操守和业务素质的有 效提升, 明确检查员的具体工作职能, 同时还需要进行考核 奖惩机制的科学构建,使相关单位工作绩效与市场信用紧密 联系, 进行检查督导制度的科学构建, 如果出现问题, 必须立 即通报处理,严禁发生质量事故。

\section{2 提升相关人员素质}

三调工作由于需要应用互联网 $+3 \mathrm{~S}$ 等融合新技术, 同时 涉及数据分析空间、数据库、计算机导航定位、地理信息测绘 等多个专业, 而且在具体进行三调工作时, 需要合理加大技 术人员投人。用中国现阶段具体工作而言,部分单位人员储 备存在很大程度的不足, 现场工作人员业务能力和技术水平 存在很大程度的差异性, 同时, 其工作经验和专业背景也具 有很大程度的不同。与此相关, 企业需要有效落实实践训练 和专业培训, 或者以小范围作为试点, 总结工作经验。与此同 时, 还可以利用传帮带形式使其相关人员技术业务能力得到 有效提升, 进一步满足生产作业需求。基于此, 在具体选择服 务单位时,需要确保相关单位管理密集, 具有较强业务技术 
地籍测绘 Cadastral Surveying and Mapping

能力, 信用度较高, 信用度高的企业, 同时还需要对其质量管 理体系进行科学完善,在开展具体工作时,需要基于不同任务 内容对其相关人员进行专业技能培训，确保相关工作规范的 全面贯彻，使其生产过程中出现的各种问题能够得到有效解 决,进而确保作业方法的正确性,保障成果质量合格。

\section{3 严格控制质量检测}

项目管理需要高度重视质量管理工作, 将建立和落实质 量管理制度作为相关工作开展的关键点，质检人员和质检机 构必须进行合理配置,明确自身工作职责。在具体进行管理工 作时, 必须确保检查内容, 要求外业抽检数量高度符合各项规 定要求, 同时还需要对其质量风险点进行评估机制的科学构 建, 实时关注风险点的具体状况, 确保首件产品检查的有效落 实。在开展下一道工序之前, 必须对上一段工序进行严格检 查, 确保符合标准之后才可以继续进行工程建设 ${ }^{[2]}$ 。在此过程 中, 如果发现问题, 必须及时处理, 实现跟踪复查制度的有效 落实,有效避免检查工作流于形式。

\section{4 明确检查重点环节}

在对三调项目进行质量控制过程中,成果汇总、数据库建 设、地类调查数据、权属调查数据、源数据、基础数据等多个方 面是较为常见的控制元素。项目建设在进行二级检查时, 需要

\section{（上接第 54 页）}

三维地理信息系统对所要查询的各种信息进行完善和整理, 使信息的查询更加方便便捷。

\section{2 .4 资源库数据的获取与更新}

三维地理信息系统通过对数据库的扩充以达到不断地获 取和更新数据的目的, 扩充数据库可以从整个世界的空间中 收集、整理、分析和储存,最后使用地理信息数据将其存人数 据库中, 从而达到对数据库的扩充, 完善数据库的数据资源。 但是世界空间内的数据变化多种多样, 情况也很复杂, 所以也 就影响三维地理信息系统对数据库的扩充与更新, 因此,GIS 的工作情况对于更新数据库有着很重要的作用。在整个空间 数据的获取与收集上,收集的方式主要有两种:一种是利用现 有的收集技术去收集, 这主要应用于那些相对来说比较容易 收集的空间数据, 收集成果后转化为 GIS 的形式存放到数据 库中; 另一种是相关技术人员通过人工的方法在各个文档、图 像、报表等各种资料中去手动查找收集,这是因为这些数据不 能被直接收集获取, 收集完毕后再通过手动的方式将数据存 储到数据库中。

\section{2 .5 对三维地理信息系统场景的展示}

三维地理信息系统对于不动产的管理和发展提供了一个
围绕作业流程开展具体工作, 在此过程中, 还需要把握关键、 突出重点。相关单位需要在整个施工过程中全面贯彻过程检 查, 尤其需要重视首件产品检查, 确保在具体工作过程中可以 及时发现问题并对其进行合理纠正, 有效避免由于错误累积, 导致出现大面积返工, 在产品检查合格之后, 才可以继续进行 下一道工序, 以此为基础,才能确保有效提升整体施工质量。 在开展具体项目建设过程中, 要对其各个工作流程质量点进 行科学梳理, 严格控制其质量, 同时对其技术人员具体工作进 行科学指导与合理纠正,避免技术路线走偏。

\section{4 结语}

总而言之, 通过科学改进组织管理, 提升相关人员素质, 严格控制质量检测, 明确检查重点环节能够确保在进行第三 次全国国土调查时对其项目成果质量进行更为有效的控制, 进而确保能够有效提升项目成果质量, 使其更高程度地满足 相关行业发展需求。

\section{参考文献}

[1]吕悦,吕伟源.农村不动产权籍调查质量控制方法 [J].北京测 绘,2019,33(4):126-130.

[2]李天. 第三次全国土地调查遥感影像质量评价方法研究 [J].城 市勘测,2019,170(2):57-60.

互惠互利的良好平台，与二维地理信息系统所局限的平面化 相比，三维地理信息系统所构建的三维立体空间模型给人的 视觉感受更加地接近现实,给用户很直观的表达效果,使用户 可以详尽、全面地去了解这个不动产项目的各个方面,极大地 推动了不动产产业的飞速发展。由于三维地理信息技术拥有 超高的标准，根据这个标准所建立的空间立体模型也就与现 实更加接近, 误差也大大减少, 使项目数据更加明确。

\section{6 结语}

总的来说,计算机产业的发展正处在突飞猛进的趋势下, 同样也带动了三维地理信息系统技术的发展, 在现实中更是 将三维地理信息系统应用于各个发展领域。本文以三维地理 信息系统对不动产的管理的应用为基础，首先介绍了三维地 理信息系统的特点与技术要求，然后对三维地理信息系统在 不动产管理方面的应用做出了详细的介绍。最后针对如何更 好地将三维地理信息系统应用于不动产的管理和登记中,这 是一个值得思考和研究的问题。

\section{参考文献}

[1]孙永泉,熊长喜,任晓聪,等.三维地理信息应用于不动产登记技 术研究 [J].河南科技,2017(9):45-46. 